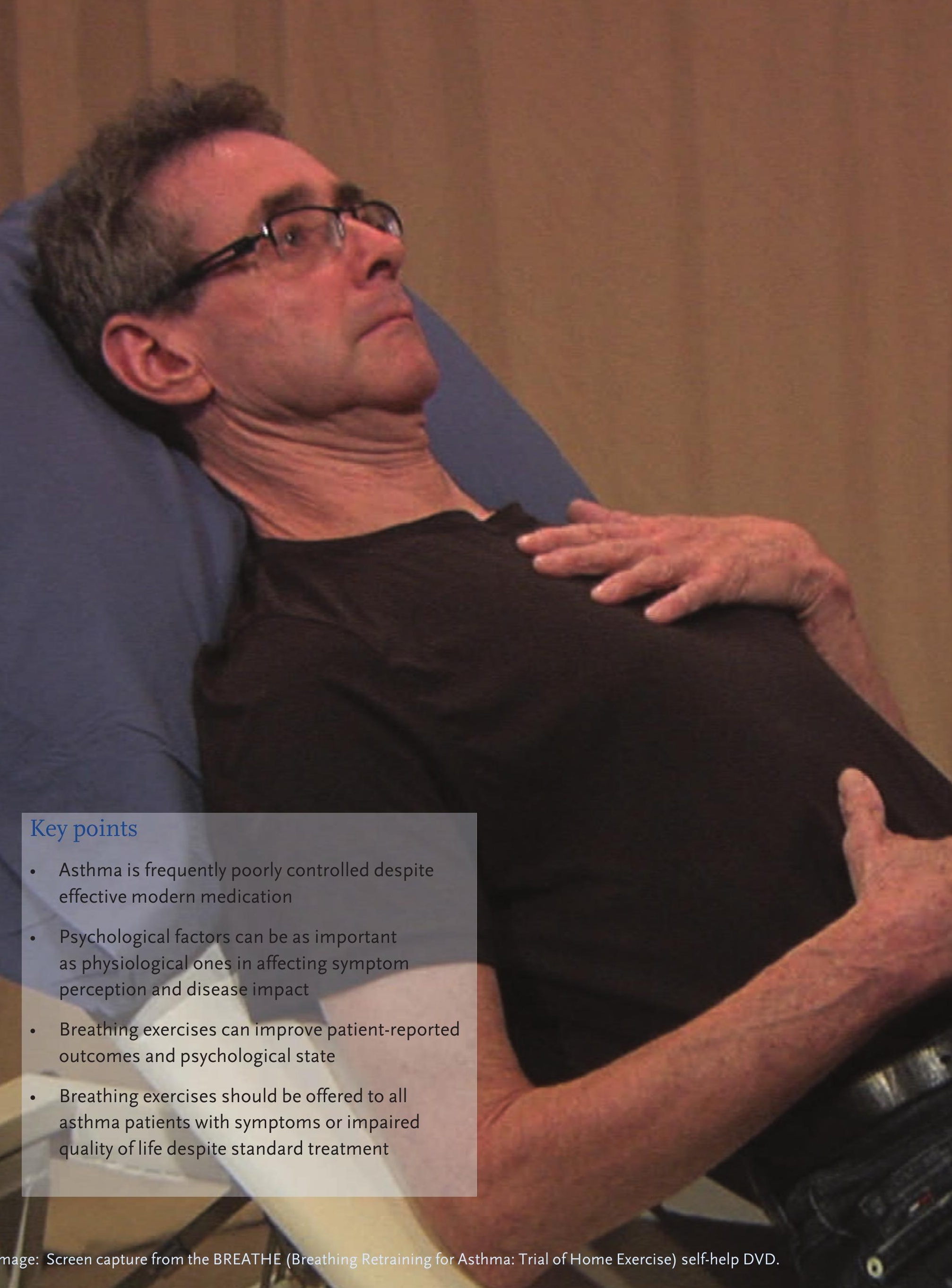




\begin{tabular}{|c|c|c|c|}
\hline $\begin{array}{l}{ }_{\text {Mike Thomas }}^{1,3,4} \text {, } \\
\text { Anne Bruton } \\
\text { 2,3,4 }\end{array}$ & $\begin{array}{l}\text { W } \\
\text { 'Primary Care and Population } \\
\text { Sciences, Faculty of Medicine, } \\
\text { University of Southampton, UK } \\
\text { 'Faculty of Health Sciences, } \\
\text { University of Southampton, UK } \\
\text { 'Southampton NIHR Respiratory } \\
\text { Biomedical Research Unit, } \\
\text { Southampton, UK } \\
\text { 4Wessex NIHR CLAHRC, } \\
\text { Southampton, UK }\end{array}$ & $\begin{array}{l}\equiv \\
\text { M. Thomas, Aldermoor } \\
\text { Health Centre, Aldermoor } \\
\text { Close, Southampton SO16 } \\
5 \text { ST. }\end{array}$ & $\begin{array}{l}\text { (2) } \\
\text { D.M.Thomas@soton.ac.uk }\end{array}$ \\
\hline
\end{tabular}

\section{Breathing exercises for asthma}

\section{Educational aims}

- To summarise the evidence of the role of breathing control approaches in the management of asthma

- To provide information on the content of evidence-based breathing exercises programmes

\section{Summary}

Asthma is a complex, multi-dimensional condition that affects patients in many ways. Having asthma is inherently stressful and psychological problems are common and associated with poor asthma outcomes. Although most patients in clinical trials can achieve high levels of control with optimised pharmacotherapy, in "real-life" practice, poor control is common, with over-reliance on rescue bronchodilator medication and ongoing symptoms and quality-of-life impairment. Many patients are interested in non-pharmacological treatments to improve asthma control, particularly breathing control exercises but, until recently, the evidence base has been inadequate. The place of breathing exercises has been controversial, partly because some proponents have made exaggerated, implausible claims of effectiveness. Recent evidence, however, has resulted in endorsement of breathing exercises as add-on treatment in asthma in systematic reviews and guidelines.

This review summarises the current evidence of effectiveness of breathing exercises programmes as an adjuvant treatment to pharmacological strategies for people with asthma. The types of breathing training programmes used and the content of effective programmes are discussed. We conclude that patients whose asthma continues to cause symptoms and quality-of-life impairment, despite adequate pharmacological treatment, or who have high bronchodilator use, should be offered access to an effective breathing training programme as a part of holistic, integrated asthma care.

Statement of Interest None declared. 


\section{Introduction: the need for innovations in asthma management strategies}

Among the outstanding achievements of modern medicine are the remarkable improvements in asthma outcomes occurring over the latter part of the last century. Although the prevalence of asthma has risen [1], improvements have occurred in hospitalisation, mortality, symptom control and quality of life (QoL). These were achieved through the widespread use of safe, effective medication and structured, proactive care [2]. Hospital-based specialist care is now reserved for those with poor control or severe, therapy-resistant disease while generalists and primary care clinicians now provide care for the majority with mild or moderate disease. It is possible that an inappropriate sense of complacency arose, with a feeling that we had "got on top" of asthma, and asthma slipped down in priority in the health agenda.

The new millennium has shown that this optimism was unwarranted; asthma is still among the most common long-term conditions, it is incurable, and outcomes have stopped improving [3]. The level of disease burden caused by asthma remains huge, resulting in levels of health impairment similar to chronic liver disease and schizophrenia [4]. Unfortunately, patients continue to die or experience life-threatening attacks, which are usually avoidable [5]. As well as these rare but severe attacks, there is also a huge burden of long-term ill health for most people with asthma. Repeated, often unpredictable, episodes of breathlessness and distressing chest symptoms are a fact of life for most people with asthma in "real-life", even for those with apparently mild disease. Surveys show that the majority of people with asthma in Europe experience regular symptoms [6] resulting in an impaired ability to lead a full, productive life, and to large direct and indirect costs [7]. Management is aimed at reducing the impact of asthma on daily life (quantified by validated questionnaires measuring symptoms, quality of life, health resource use and biomarkers of disease activity) and the risk of future adverse events (such as death, hospitalisation, exacerbations and permanent lung damage) [8]. Surveys of asthma control have shown little or no recent improvements in any of these outcomes in most developed countries. In the UK, for instance, mortality and hospitalisation rates are static [9, 10], with marked regional variations [11]. The majority of European patients continue to report significant symptoms [6] other than in countries that have prioritised asthma as a public health problem [12]. This has occurred at a time when we have had a stream of new licensed asthma products and evidence that, in closely controlled clinical trial settings, most can achieve good control [13]. Is there an element to treating asthma that we are missing out on? In particular, are there non-pharmacological strategies that we could be using to help our patients cope better and to reduce the impact of asthma on their lives?

\section{Asthma outcomes and the "whole patient": beyond the pharmacological}

The "stepped" pharmacotherapy strategy familiar from asthma guidelines may encourage the belief that stronger medication is needed when control is poor. Some patients do indeed have severe, therapy-resistant disease, requiring more effective pharmacotherapy. However, good-quality management (including self-management education and treating co-morbidities) can often improve outcomes even in this group [14], and psychosocial problems and non-adherence are common in people with asthma of all severity levels. Asthma is incurable and usually a lifelong condition, and the recurrent and unpredictable experience of having to struggle to breathe is frightening and disturbing, potentially undermining overall wellbeing. If other life stressors are present, such as co-morbidity, psychosocial disadvantage or a lack or resilience to stress resulting from genetic or environmentally factors, some will experience symptoms as more distressing and may not cope with them well.

Clinicians recognise that some people cope better with illness than others. Some cope well despite objectively severe disease and poor lung function, but others report high symptom loads, multiple perceived 
problems and restricted quality of life despite apparently mild disease. Symptoms and quality of life correlate poorly with "objective" physiological and pathological parameters of disease control $[15,16]$, and are more strongly correlated with psychosocial measures [17]. Socio-economic factors, multimorbidities and psychological state [18], have strong and independent associations with all asthma outcomes, and the strongest independent predictor of the unpleasantness of breathlessness for a given degree of bronchoconstriction during a challenge test is anxiety [19]. Quality of life, symptoms, health resource use, exacerbation rate and even deaths are independently related to psychological state, with psychiatric co-morbidity accounting for $29 \%$ of symptom variance in one report [20].

Psychological dysfunction is generally found to be up to six-times as common in people with asthma [18], with asthma-related QoL correlating better with psychosocial factors than lung function or treatment step [21]. Underlying mechanisms are incompletely understood but probably relate to several overlapping biological and behavioural factors. Functional neuroimaging studies show that brain structures mediating breathlessness are related anatomically and functionally to those processing emotions [22], and that emotional state may influence immunological responses, for example to aeroallergens [23]. Anxiety is associated with worsened selfmanagement behaviour [24].

Over-breathing (hyperventilation) and abnormal breathing patterns (dysfunctional breathing) are commonly associated with anxiety, and breathing-control exercises have long been used as a treatment for anxiety and panic. Hyperventilation and other abnormalities in breathing have also been associated with asthma, implicated as triggers for bronchoconstriction and the production of asthma-like symptoms in patients of all levels of objective asthma severity [25].

A certain amount of anxiety is natural and inevitable with distressing symptoms, such as dyspnoea, and can promote appropriate responses such as seeking help or using necessary medication. Excessive anxiety or inappropriate responses, however, can result in a "negative feedback" situation of worsening symptoms leading to further emotional and cognitive distress, often involving overbreathing or abnormal unstable breathing, and with poor self-management behaviour. As a consequence, a number of different types of breathing-control techniques have been advocated for treating asthma.

\section{Breathing exercises for asthma}

Breathing exercises for asthma can be broadly divided into three groups: exercises aimed at manipulating the pattern of breathing (breathing retraining); exercises aimed at increasing the strength and/or endurance of the respiratory muscles (respiratory muscle training); and exercises aimed at increasing the flexibility of the thoracic cage and improving posture (musculoskeletal training). In this article, we will focus on breathing retraining techniques, because these currently have the strongest and most convincing evidence base for effectiveness in asthma and are the most widely practiced. It should be noted that although many practitioners are applying these techniques clinically to children and teenagers, the only robust current research trial evidence applies to adults, with a recent Cochrane search for evidence in other age groups finding zero papers for inclusion in their review [26].

Breathing retraining for asthma is a specific area of breathing exercise therapy that, after several years of relative neglect, has seen a considerable resurgence in research activity over the last decade. The breathing training techniques most frequently investigated have been physiotherapist-administered breathing exercises [27-30], as well as alternative techniques, such as the Buteyko breathing method [31-33] and yogic breathing $[34,35]$. Of these, physiotherapy and Buteyko have the higher level of evidence and are now mentioned in several guidelines for asthma management.

\section{Breathing retraining}

\begin{abstract}
Aims
The aims of breathing training (table 1 ) are to "normalise" breathing patterns, usually by adopting a slower respiratory rate with longer expiration and reduction in overall ventilation [36]. Use of abdominal rather than the upperchest and accessory muscles of ventilation in resting breathing, and nasal rather than
\end{abstract}


mouth breathing are also frequently stressed. The rationale for this training is based on the assumption that people with asthma have abnormal or dysfunctional breathing patterns. The evidence for this assumption is fairly weak, as few reliable studies have compared breathing patterns in people with asthma to healthy subjects. People with asthma (even mild well-controlled asthma) do have on average a lower arterial and end-tidal carbon dioxide tension than matched non-asthmatic subjects, indicating a tendency to over-breathe [37]. There is indirect evidence from surveys from the UK reporting one-third of women and one-fifth of men treated for asthma in general practice have had symptoms suggestive of hyperventilation or "dysfunctional" breathing [25], and from Spain where one-third of asthma patients in a Spanish pulmonology clinic had such symptoms [38]. Approximately one-fifth of patients attending UK difficult asthma clinics were found after detailed assessment to have functional breathing disorders (including dysfunctional breathing and vocal cord dysfunction) as a major factor in their illness [39].

\section{Method of delivery}

Breathing training for asthma should be considered as a complex multicomponent behavioural change intervention involving both instructional and practice phases. In clinical practice, the instruction phase of the intervention is conventionally delivered individually via face-to-face methods between a patient and a therapist. Although some studies have used small-group delivery, no direct comparisons have yet been trialled for group versus one-toone delivery. Some trials have used alternative "distance" delivery methods, such as video/ DVD in an Australian study [40] investigating the effects of two breathing training programmes delivered as a videotaped instruction programme. Both programmes were associated with improved health status and major reductions in bronchodilator use from baseline values. They have subsequently been made available as Internet downloads and used in Australia to improve asthma control in routine practice. The minimum length and number of instruction sessions required to achieve improvement is not known and, in clinical practice, they tend to be individualised according to the needs of the patient. In our experience with physiotherapy breathing retraining, 3-4 sessions spread over a period of about 6 weeks are effective. The typical content of these sessions can be seen in figure 1.

Patients are then encouraged to put the various techniques into practice on a daily basis and to try to incorporate them into daily routines until they become "second nature" and embedded into daily life. The ideal number and duration of practice sessions is also unknown and, as with the instruction sessions, is likely to vary between individuals.

\section{Programme content}

Breathing training generally involves a package of components. The Papworth (physiotherapy), Yoga and Buteyko packages all have different underlying philosophies but also have some core similarities, with breathing pattern modification being the primary component. Other common elements are advice on route of breathing, breath holding, relaxation and home exercises. More variable elements are nutritional advice, medication usage advice, asthma education, aerobic exercise prescription and use of biofeedback (e.g. capnometry or breathing rate).

\section{Breathing-pattern modification}

At the core of all packages is breathingpattern modification. The main components

Table 1. Aims of breathing retraining for asthma with the proposed mechanisms of benefit

Aims of breathing retraining
1. Reduce breathing rate
2. Reduce breathing volumes
3. Increase use of abdominal/ lower thoracic chest movement
4. Use nasal route of breathing
5. Encourage relaxation

\section{Potential mechanisms}

Reduce over-breathing (1-5)

Reverse hypocapnia if present ( 1 and 2 )

Reduce airflow turbulence ( 1 and 4 )

Reduce hyperinflation (1, 2 and 4 )

Reduce variability of breathing pattern (1, 2 and 4)

Reduce anxiety (1-5)

Provide deferment strategy (1-5) 


\section{Typical content of 3 face-to-face physiotherapy breathing retraining sessions}

\section{Session 1}

Duration: $30-45$ minutes.

Summary: Session 1 contains teaching the use of the abdomen (rather than upper chest) and the importance of nasal breathing. Slow breathing may also be taught.

Position: Patient should be comfortably positioned sitting with legs outstretched on a couch with raised (roughly 45 degrees) support for the head and back.

Content:

- Check understanding of asthma and how it affects their breathing

- Check understanding that breathing pattern may affect symptoms

- Check understanding of breathing training potential benefits for breathlessness: both in general and specifically for them

- Make aware that they need to continue to take all medication as usual

- Make aware that no harm can occur through breathing retraining

- Advice on use of lower thoracic and abdominal expansion versus upper chest expansion

- $\quad$ Advice on nose breathing

- $\quad$ Give home advice about activities for use between sessions

Breathing control is defined as breathing at normal rate and depth initially, but using only lower thoracic and abdominal compartment expansion (also known as diaphragmatic breathing).

Home advice:

- Advised to practice twice daily, steadily increasing the amount of time spent

- $\quad$ Advised to use a mirror for feedback

- $\quad$ Advised to use the taught positions for relieving breathlessness: forward lean standing/sitting

Session 2

Duration: $30-40$ minutes.

Summary: Review of progress and problems and review of abdominal breathing technique. The second session teaches slow breathing, controlled breath holds, reduced volume and flow breathing, paced breathing and general relaxation techniques.

Position: Comfortably positioned in sitting or lying down for relaxation exercises

Content:

- $\quad$ Review of session 1: adherence to home exercises

- Teach/check slow abdominal breathing control technique in half-lying and/or sitting position

- Encourage to reduce flow rate on inspiration, and passive expiration

- Encourage to reduce inspired volumes for short periods

- Teach use of maximal breath holds as a monitor of progress

- Encourage nose breathing at all times

- Teach paced breathing while walking (e.g. breathe in for two steps, breathe out for three steps)

- Teach controlled expiratory breath holds: pinch nose and hold breath at end expiration after a normal tidal breath. Hold breath until need to inhale is felt, inhale through nose with a relaxed breath. Patients asked to do $3-4$ in a row with a rest (of $30-40 \mathrm{~s}$ ) in between each

Teach relaxation techniques (e.g. contract-relax)

Home advice:

- $\quad$ Continue slow abdominal breathing control exercises twice daily

- $\quad$ Practice slower rates and reduced volumes while sitting

- $\quad$ Abdominal and nasal breathing whilst walking/during normal activity

- $\quad$ Practice controlled breath holds twice daily

- Relaxation technique once daily minimum

- Use of maximal breath-hold once per week to assess progress.

Session 3

Duration: $20-30$ minutes.

Summary: Review of progress and problems. The third session reinforces techniques not mastered in session 2, provides feedback on performance, plus advice for use of the techniques in their daily life.

Content:

- Review of session 2: general adherence to home exercises estimated

- Slow abdominal breathing control technique assessed

- Breathing pattern in sitting, standing and walking assessed

- Breath holds at rest assessed: both controlled pauses and maximal holds

- Relaxation technique assessed

Home advice:

- Home incremental exercise programme

- Use of abdominal breathing to be practiced in new daily situations e.g. shopping, working or during housework

- Maximal breath holds as monitor of progress

- Continue to breathe via the nose at all times.

\section{Figure 1}

Typical content of face-to-face breathing retraining sessions

that may be modified are rate of breathing (number of breaths per minute), depth of breathing (volume of air inspired per breath), airflow velocity (flow rate), timing (inspiratory/ expiratory phase, duration, ratio and pauses), rhythm of breathing (within-individual variability of rate, volume and timing) and primary region of movement (upper thoracic 
expansion, lower thoracic expansion, abdominal expansion). Although there is no evidence that altering chest movement affects regional distribution of ventilation, it has been proposed that the abnormal afferent proprioceptive input associated with an upper thoracic breathing pattern can directly result in increased perception of respiratory symptoms [41].

Each of these components can be altered depending on the desired effect. All programmes aim to reduce breathing rate and physiotherapy, and Buteyko additionally aims to reduce overall ventilation. This requires attention to be paid not only to rate, but also to depth of breathing. A slower rate can be achieved but if inspired tidal volume is allowed to increase, this may result in unchanged minute ventilation. It is generally easier to teach slowing the rate first, before attempting to control volume. A slower rate is achieved through prolonging the expiratory phase and increasing pause times. There are theoretical benefits from altering the inspiratory:expiratory ratio to permit longer expiratory times and potentially reduce hyperinflation. The majority of stable asthma patients do not exhibit tidal expiratory flow limitation at rest, but both expiratory flow limitation and dynamic hyperinflation are common during exercise [42].

Breathing pattern re-trainers frequently describe the need to "regularise" the breathing pattern, i.e. to reduce the variability of rate and depth. There is limited evidence for increased pattern variability in asthma [43], but there is theoretical and pragmatic support for encouraging regularity. The effect of the rhythmic cycling associated with tidal breathing in decreasing airway smooth muscle tone has been reported from both in vivo and in vitro studies [44].

\section{Nasal breathing}

Breathing may occur through the nose or the mouth, and the biological role of nasal breathing is to filter, warm and humidify inspired air, all potentially important factors in minimising the impact of asthma. The route of breathing in asthma is infrequently reported, although mouth breathing may be frequently observed in people with asthma (sometimes an association with co-morbid allergic rhinitis, a treatable condition), and asthma outcomes may be worse in those with co-morbid nasal disease [45]. One study specifically reporting on route of breathing found the oral route common during exacerbations [46]. In people with asthma, nose breathing has been associated with a reduction in night-time episodes [47] and a reduction in inspired flow velocity [48]. Mouth breathing may be associated with worsened asthma symptoms, with one study [49] reporting that enforcing oral breathing for adult asthma volunteers resulted in the development of asthma symptoms in a third, and a progressive reduction in forced expiratory volume in $1 \mathrm{~s}$ over 6o-minutes of oral breathing, compared with nasal breathing.

\section{Use of breath holds/pauses}

One of the common components of those breathing training packages that have been tested in published randomised controlled trials is the use of breath holds or pauses. Breath holding has multiple theoretical benefits. For example, end-inspiratory breath holds of $3 \mathrm{~s}$ are used to make use of collateral ventilation in patients with reduced ventilation or retained secretions. The aim is to improve distribution of ventilation and allow air to get behind secretions [50]. Proposed, but unproven, benefits of breath holds are to desensitise individuals to raised carbon dioxide tensions and to reduce respiratory rate [51]. However, even an apparently simple technique such as breath holding contains hidden complexity. Breath holds can be: inspiratory or expiratory; held at various volumes (such as maximal inspiration or functional residual capacity); held for varying durations using different break-points; held during rest or during activity; involve nose holding or not. This level of detailed description is not generally available in published trials. Physiotherapists in our local area use end-expiratory breath holds (at functional residual capacity), with the nose held, and holds are sustained to the point of discomfort, but not for so long that the patient has to take a deep breath afterwards.

\section{Evidence for breathing exercises in asthma}

Although breathing excises might be viewed as a novel, perhaps even "new-age", treatment, breathing control and relaxation exercises have a long pedigree and were a major 
component of asthma treatment in the era before effective inhaled treatment: many older asthmatics will recall being instructed in breathing techniques in their youth. Despite this, breathing control had largely disappeared from routine care until a recent revival of interest, although surveys of complementary and alternative medicine use have shown that many patients have used breathing control, often without the knowledge of their medical attendants. Due to the recent expansion in research, there is now a greatly improved evidence base. Breathing training techniques investigated have included physiotherapistadministered breathing exercises [28-30], the Buteyko breathing method [31-33] and Yoga breathing [34, 35]. Many clinicians have been sceptical about the role of breathing training in asthma, partly due to exaggerated and unsubstantiated claims made by proponents of specific packages, particularly Buteyko practitioners. However, there is now a convincing body of evidence that breathing training for people with asthma is effective in improving patient-reported endpoints, such as symptoms, health status and psychological well-being, and may be effective in reducing rescue bronchodilator medication usage. There is currently no convincing evidence that breathing training has an effect on airway inflammation or physiology.

Two recent systematic reviews have formally assessed the evidence. A systematic review of breathing exercises and/or retraining techniques in the treatment of asthma performed for the US Agency for Healthcare Research and Quality [52] found 22 studies. Although these were heterogeneous in terms of methodology, intervention and quality, the review found that hyperventilation-reduction techniques achieved a medium-to-large reduction in symptoms and reduction in medication use (1.5-2.5 puffs of $\beta_{2}$-agonist per day), although with no improvement in pulmonary function. Generally, improvements were seen in patient-reported outcome measures, particularly quality of life, rescue medication requirement and symptoms, with lesser or absent improvements in physiological disease parameters. The review concluded that "behavioral approaches that include hyperventilation reduction techniques can improve asthma symptoms or reduce reliever medication use over 6 to 12 months in adults with poorly controlled asthma and have no known harmful effects." An updated Cochrane review in 2013 of "Breathing exercises for adults with asthma" [53] with more restrictive criteria considered 13 studies involving 906 participants. Again, considerable heterogeneity was found, but six out of seven studies reporting symptom control showed significant differences favouring breathing exercises. All eight studies that assessed quality of life reported an improvement in this outcome. Effects on lung function were more variable, with no difference reported in five out of the 11 studies, while the other six showed a significant difference favouring breathing exercises. Meta-analysis was possible only for symptoms and quality of life, and showed a significant difference favouring breathing exercises for both parameters. Recent guidelines have come to similar conclusions, with the latest Global Initiative for Asthma (GINA) iteration stating that "breathing exercises may be a useful supplement to medications" [54]. The recently updated non-pharmacological management section of the British Thoracic Society (BTS)/ Scottish Intercollegiate Guidelines Network (SIGN) UK Asthma Guideline [55] gives grade-A recommendation to the statement "Breathing exercise programmes (including physiotherapist-taught methods) can be offered to people with asthma as an adjuvant to pharmacological treatment to improve quality of life and to reduce symptoms", based on evidence graded as $1++$. This should now be a standard part of the range of treatments offered to patients.

\section{Targeting: who benefits from breathing training?}

Asthma encompasses a variety of phenotypes, and different therapeutic approaches may be effective in different patients [56]. At present, data from published trials suggest that those who would benefit most from breathing training seem to be those with impaired quality of life (when assessed with a validated questionnaire, such as the Asthma Quality of Life Questionnaire) despite standard medication (which currently applies to over half of those labelled with, and treated for, asthma in Europe). Although intuitively one might think those with symptoms of hyperventilation would be more likely to benefit, in the largest trial to date, no significant difference in response to training from those with higher hyperventilation symptom scores (evaluated using the

\section{Educational questions}

1. Asthma mortality and hospitalisation rates in most

European countries since 2000:

a) Are reducing

b) Are increasing

c) Are static

2. The proportion of patients with good asthma symptom control in Europe is:
a) $>80 \%$
b) $50-80 \%$
c) $30-50 \%$
d) $<30 \%$

3. How common is psychological dysfunction in patients with asthma?

a) Twice as common as in the general population

b) Less common than in the general population

c) Ten-times as common as in the general population

d) Six-times as common as in the general population

4. Which of the following are aims of breathing retraining programmes in asthma?

a) Reduce respiratory rate

b) Increase respiratory muscle strength

c) Increase minute volume

d) Increase abdominal and lower chest movement

e) Increase nasal breathing

f) Improve depression 
5. Breathing exercises for asthma patients should be

a) Those with evidence of hyperventilation such as hypocapnia or raised minute volume

b) Those with a diagnosis of anxiety or depression

c) Those with impaired asthmarelated quality of life

d) Those with high scores on a hyperventilation questionnaire confined to:

Nijmegen questionnaire) or lower baseline carbon dioxide tension [28]. Similarly, clinically diagnosed or screening-revealed anxiety and depression did not predict the response to treatment in current trials [28]. Despite the improvements in patient reported outcomes, however, none of the RCTs to date have reported sufficiently detailed information on breathing pattern before and after breathing training to establish if a) breathing pattern at baseline is genuinely abnormal and b) if it alters after a breathing training intervention. Breathing retraining requires a commitment from the individual patient in terms of time and effort. It suits those who are happy to be involved with self-management but is unlikely to be effective in patients who prefer a "quick fix", or who lack sufficient motivation to practice and sustain the techniques alone. However, for patients who are not achieving adequate control despite apparently adequate pharmacological treatment, informing them of the possibility of breathing control and referring them to an appropriate source of instruction would be in agreement with current evidence and guidelines.

\section{Integrating breathing exercises into routine care}

A problem for many clinicians and patients is accessing therapists who can provide this

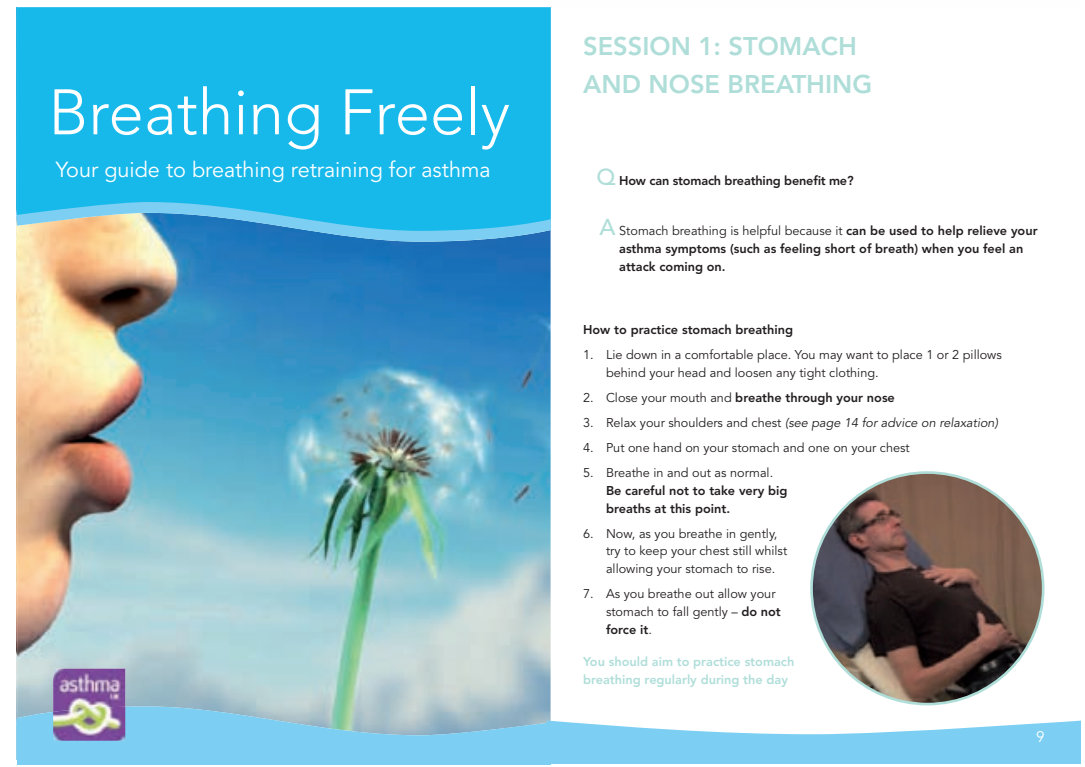

Figure 2

Example of patient self-help material from the BREATHE (Breathing Retraining for Asthma: Trial of Home Exercises) study [57] training, which can be problematic for many respiratory specialists, and more so for community-based generalists. The cost-effectiveness of increasing access to respiratory physiotherapists or other suitable professionals has not been assessed. Currently many patients who are interested in this type of treatment can only access it by paying unregulated therapists or by self-help books, internet pages or YouTube videos of unknown efficacy. Many clinicians are unable to conveniently access such treatments so are unfamiliar with the benefits that can be provided to their patients from it. We feel that all clinics providing care to those with difficult-to-control asthma should include professionals skilled in the detection of behavioural and psychological issues in holistic asthma care and have routine access to breathing training programmes for suitable patients. The use of validated questionnaires measuring psychological health would be useful, although clinics incorporating health psychology expertise report good results.

There is, however, also potential for this approach to benefit many patients treated in the community whose asthma is mild to moderate but who have on-going health impairment. We are currently investigating the clinical and cost-effectiveness of an interactive "digital" audio-visual breathing training programme (which can be delivered by the internet or DVD) with written supporting material, compared to face-to-face programmes and usual care, in the BREATHE (Breathing Retraining for Asthma: Trial of Home Exercises) study (fig. 2) [57]. Potentially, this could allow a method of allowing large numbers of people to access the treatment in a convenient and inexpensive way.

\section{Conclusion}

Asthma is a complex, multi-faceted condition, and control is sub-optimal for most patients. As asthma cannot be cured, recurrent symptoms results in distress and in increased life-stress that may lead to psychological dysfunction (associated with worsened asthma outcomes) for some. There is now a compelling body of evidence showing that instruction in fairly simple breathing exercises provided by a trained therapist can improve patients' experience of their disease and 
reduce their reliance on rescue medication. Many patients will explore breathing-control techniques independently of their doctors, which may result in expense, inconvenience, exposure to less effective techniques and misinformation. It is possible to provide evidence-based, rational and acceptable breathing training programmes as part of an overall integrated asthma service and many patients can benefit from this approach. Access to trained therapists is an on-going issue, but future research may allow greater access to effective programmes.

\section{References}

1. Eder W, Ege MW, von Mutius E. The asthma epidemic. N Eng J Med 2006; 335: 2226-2235.

2. Tattersfield AE, Knox AJ, Britton JP, et al. Asthma. Lancet 2002; 360: 1313-1322.

3. Martinez FD, Vercelli D. Asthma. Lancet 2013; 382: 1360-1372.

4. Masoli M, Fabian D, Holt S, et al. The global burden of asthma: executive summary of the GINA Dissemination Committee report. Allergy 2004; 59: 469-478.

5. Levy M, Andrews R, Buckingham R, et al. Why asthma still kills: the National Review of Asthma Deaths (NRAD) Confidential Enquiry report. London: RCP, 2014. Available from: www.rcplondon.ac.uk/ sites/default/files/why-asthma-still-kills-full-report.pdf date last updated: May 2014. Date last accessed: October 272014.

6. Demoly P, Gueron B, Annunziata K, et al. Update on asthma control in five European countries: results of a 2008 survey. Eur Respir Rev 2010; 19: 150-157.

7. Barnes PJ, Jonsson B, Klim JB. The costs of asthma. Eur Respir J 1996; 9: 636-642.

8. Reddel HK, Taylor DR, Bateman ED, et al. An official American Thoracic Society/European Respiratory Society statement: asthma control and exacerbations: standardizing endpoints for clinical asthma trials and clinical practice. Am J Respir Crit Care Med 2009; 180: 59-99.

9. Department of Health Medical Directorate Respiratory Team. An Outcomes Strategy for COPD and asthma. 2011. Available from www.gov.uk/ government/uploads/system/uploads/attachment_data/ file/216139/dh_128428.pdf Date last updated: July 2011. Date last accessed: October 272014.

10. Anderson HR, Gupta R, Strachan DP, et al. 50 years of asthma: UK trends 1955-2004. Thorax 2007; 62: 85-90.

11. NHS Atlas of Variation in Healthcare for People with Respiratory Disease. 2012. Available from www. rightcare.nhs.uk/atlas/ Date last accessed: October 272014 .

12. Haahtela T, Tuomisto LE, Pietinalho A, et al. A 10year asthma programme in Finland: major change for the better. Thorax 2006; 61: 663-670.

13. Bateman ED, Boushey HA, Bousquet J, et al. Can guideline-defined asthma control be achieved? The Gaining Optimal Asthma ControL study. Am J Respir Crit Care Med 2004; 170: 836-844.

14. Chung KF, Wenzel SE, Brozek JL, et al. International ERS/ATS guidelines on definition, evaluation and treatment of severe asthma. Eur Respir J 2014; 43: $343-373$.

15. Teeter JG, Bleecker ER. Relationship between airway obstruction and respiratory symptoms in adult asthmatics. Chest 1998; 113: 272-277.
16. Juniper EF, Wisniewski ME, Cox FM, et al. Relationship between quality of life and clinical status in asthma: a factor analysis. Eur Respir J 2004; 23: 287-291.

17. Rimington LD, Davies DH, Lowe D, et al. Relationship between anxiety, depression, and morbidity in adult asthma patients. Thorax 2001; 56: 266-271.

18. Thomas M, Bruton A, Moffat M, et al. Asthma and psychological dysfunction. Prim Care Respir J 2011; 20: $250-256$.

19. Spinhoven P, Peski-Oosterbaan AS, Van der Dooes AJ, et al. Association of anxiety with perception of induced bronchoconstriction in patients with asthma. Thorax 1997; 52: 149-152.

20. Lavoie KL, Bacon SL, Barone S, et al. What is worse for asthma control and quality of life: depressive disorders, anxiety disorders, or both? Chest 2006; 130: 1039-1047.

21. Moy ML, Lantin ML, Harver A, et al. Language of dyspnea in assessment of patients with acute asthma treated with nebulized albuterol. Am J Respir Crit Care Med 1998; 158: 749-753.

22. von Leupoldt A, Sommer T, Kegat $\mathrm{S}$, et al. The unpleasantness of perceived dyspnea is processed in the anterior insula and amygdala. Am J Respir Crit Care Med 2008; 177: 1026-1032.

23. Rosenkranz MA, Busse WW, Sheridan JF, et al. Are there neurophenotypes for asthma? Functional brain imaging of the interaction between emotion and inflammation in asthma. PLoS One 2012; 7: e40921.

24. Bender BG. Risk taking, depression, adherence, and symptom control in adolescents and young adults with asthma. Am J Respir Crit Care Med 2006; 173: 953-957.

25. Thomas M, McKinley RK, Freeman E, et al. Prevalence of dysfunctional breathing in patients treated for asthma in primary care: cross sectional survey. BMJ 2001; 322: 1098-1100.

26. Barker NJ, Jones M, O'Connell NE, et al. Breathing exercises for dysfunctional breathing/hyperventilation syndrome in children. Cochrane Database Syst Rev 2013; 12: CDo10376.

27. Laurino RA, Barnabé V, Saraiva-Romanholo BM, et al. Respiratory rehabilitation: a physiotherapy approach to the control of asthma. Symptoms and anxiety. Clinics (Sao Paulo) 2012; 67: 1291-1297.

28. Thomas M, McKinley RK, Mellor S, et al. Breathing exercises for asthma: a randomised controlled trial. Thorax 2009; 64: 55-61.

29. Holloway EA, West RJ. Integrated breathing and relaxation training (the Papworth method) for adults with asthma in primary care: a randomised controlled trial. Thorax 2007; 62: 1039-1043.

30. Thomas M, McKinley RK, Freeman E, et al. Breathing retraining for dysfunctional breathing in asthma- a randomised controlled trial. Thorax 2003; 58: 110-115.
Suggested answers

1. C.

2. C.

3. d.

4. a, d and e.

5. c. 
31. Cowie RL, Conley DP, Underwood MF, et al. A randomised controlled trial of the Buteyko technique as an adjunct to conventional management of asthma. Respir Med 2008; 102: 726-723.

32. Opat AJ, Cohen MM, Bailey MJ, et al. A clinical trial of the Buteyko breathing technique in asthma as taught by a video. J Asthma 2000; 37: 557-564.

33. Cooper S, Oborne J, Newton FS. Effect of two breathing exercises (Buteyko and pranayama) in asthma: a randomised controlled trial. Thorax 2003; 58: 674-679.

34. Singh V, Wisniewski A, Britton J, et al. Effect of yoga breathing exercises (pranayama) on airway reactivity in subjects with asthma. Lancet 1990; 335: 1381-1383.

35. Manocha R, Marks GB, Kenchington P. Sahaja yoga in the management of moderate to severe asthma: a randomised controlled trial. Thorax 2002; 57: 110-115.

36. Ritz T, Roth WT. Behavioral interventions in asthma. Breathing training. Behav Modif 2003; 27: 710-730.

37. Osborne CA, O'Connor BJ, Lewis A, et al. Hyperventilation and asymptomatic chronic asthma. Thorax 2000; 55: 1016-1022.

38. Martínez-Moragón E, Perpiñá M, Belloch $A$, et al Prevalence of hyperventilation syndrome in patients treated for asthma in a pulmonology clinic. Arch Bronconeumol 2005; 41: 267-271.

39. Heaney LG, Robinson DS. Severe asthma treatment: need for characterising patients. Lancet 2005; 365: 974-976.

40. Slader CA, Reddel HK, Spencer LM, et al. Double blind randomised controlled trial of two different breathing techniques in the management of asthma. Thorax 2006; 61: 651-656.

41. Howell JB. The hyperventilation syndrome: a syndrome under threat? Thorax 1997; 52: Suppl. 3, S30-S34.

42. Kosmas EN, Milic-Emili J, Polychronaki A, et al. Exercise-induced flow limitation, dynamic hyperinflation and exercise capacity in patients with bronchial asthma. Eur Respir J 2004; 24: 378-384.

43. Prys-Picard CO. Disproportionate breathlessness associated with deep sighing breathing in a patient presenting with difficult-to-treat asthma. Chest 2006; 130: $1723-1725$.

44. Brown RH, Mitzner W. Airway response to deep inspiration: role of nitric oxide. Eur Respir J 2003; 22: 57-61.

45. Price D, Kocevar VS, Zhang Q, et al. Effect of a concomitant diagnosis of allergic rhinitis on asthmarelated health care use by adults. Clin Exp Allergy 2005; 35: 282-287.
46. Kairaitis K, Garlick SR, Wheatley JR, et al. Route of breathing in patients with asthma. Chest 1999; 116: $1646-1652$.

47. Petruson B, Theman K. Reduced nocturnal asthma by improved nasal breathing. Acta Otolaryngol 1996; 116: 490-492.

48. Chowdhary $R$, Singh $V$, Tattersfield $A E$, et al. Relationship of flow and cross-sectional area to frictional stress in airway models of asthma.J Asthma 1999; 36: 419-426.

49. Hallani M, Wheatley JR, Amis TC. Enforced mouth breathing decreases lung function in mild asthmatics. Respirology 2008; 13: 553-558.

50. Mcllwaine M. Physiotherapy and airway clearance techniques and devices. Paediatr Respir Rev 2006; 7: Suppl. 1, S220-S222.

51. Courtney R, Cohen M. Investigating the claims of Konstantin Buteyko MD PhD: the relationship of breath holding time to end tidal $\mathrm{CO}_{2}$ and other proposed measures of dysfunctional breathing. J Altern Complement Med 2008; 14: 115-123.

52. O'Connor E, Patnode CD, Burda BU, et al. Eds. Breathing Exercises and/or Retraining Techniques in the Treatment of Asthma: Comparative Effectiveness. Comparative Effectiveness Reviews, No. 71. Report: 12-EHCog2-EF. Rockville, Agency for Healthcare Research and Quality (US); 2012.

53. Freitas DA, Holloway EA, Bruno SS, et al. Breathing exercises for adults with asthma. Cochrane Database Syst Rev 2013; 10: CDoo1277.

54. Global Strategy for Asthma Management and Prevention, Global Initiative for Asthma (GINA). Available from www.ginasthma.org/documents/4 Date last updated: August 2014. Date last accessed: October 27, 2014. 2014.

55. British Thoracic Society, Scottish Intercollegiate Guideline Network. British Guideline on the Management of Asthma, 2014. www.brit-thoracic. org.uk/document-library/clinical-information/asthma/ btssign-asthma-guideline-2014 Date last updated: October 2014. Date last accessed: October 272014.

56. Anderson GP. Endotyping asthma: new insights into key pathogenic mechanisms in a complex, heterogeneous disease. Lancet 2008; 372: 1107-1119.

57. Bruton A, Kirby S, Arden-Close E, et al. The BREATHE study: Breathing REtraining for Asthma: Trial of Home Exercises. A protocol summary of a randomised controlled trial. Prim Care Respir J 2013; 22: PS1-PS7. 